\title{
Infectious Complications after Cesarean Delivery: Trends of Incidences, Risk Factors, and Prognosis in a Third Health Level Center in Africa. Case of Gabriel Touré Teaching Hospital
}

\author{
Youssouf Traoré ${ }^{*}$, Ibrahima Téguété ${ }^{1}$, Amadou Bocoum ${ }^{1}$, Malado Gamby ${ }^{1}$, Sidy Traore ${ }^{1}$, \\ Soumaila Sanogo ${ }^{1}$, Seydou Zana Dao², Mamadou S. Traoré3, Niani Mounkoro ${ }^{1}$
}

${ }^{1}$ Department of Gynecology and Obstetrics, Gabriel Touré Teaching Hospital, Bamako, Mali

${ }^{2}$ Department of Gynecology and Obstetrics, Commune II Health Center, Bamako, Mali

${ }^{3}$ Department of Gynecology and Obstetrics, Point G Teaching Hospital, Bamako, Mali

Email: *dryoussouf.traore@gmail.com

How to cite this paper: Traoré, Y., Téguété, I., Bocoum, A., Gamby, M., Traore, S., Sanogo, S., Dao, S.Z., Traoré, M.S. and Mounkoro, N. (2018) Infectious Complications after Cesarean Delivery: Trends of Incidences, Risk Factors, and Prognosis in a Third Health Level Center in Africa. Case of Gabriel Touré Teaching Hospital. Open Journal of Obstetrics and Gynecology, 8, 10-19.

https://doi.org/10.4236/ojog.2018.81002

Received: November 17, 2017

Accepted: January 1, 2018

Published: January 4, 2018

Copyright $\odot 2018$ by authors and Scientific Research Publishing Inc. This work is licensed under the Creative Commons Attribution International License (CC BY 4.0).

http://creativecommons.org/licenses/by/4.0/

\section{Abstract}

Post cesarean infections are the main sources of fever in the postpartum. We have undertaken this study in an African health setting where conditions of working are different from those in developed countries. Objectives: The objectives of this survey were to appreciate incidences, risk factors and prognosis of post cesarean infections. Method: We conducted a randomized historical cohort study in the department of gynecology and obstetrics of Gabriel Touré teaching hospital from 2010 to 2015. Data have been analyzed using $\mathrm{X}^{2}$ or Fisher test according their application conditions, $p$ value $<1 \%$ has been considered significant. Results: From 2010 to 2015 we performed 15,963 deliveries within 5263 cesareans sections (32.97\%). According to all the deliveries, the global frequency of infection fluctuates from $1.5 \%$ in 2010 to $2.1 \%$ in 2015 . The main risks that influenced the occurrence of post cesarean infections were: the context of cesarean section $\left(\mathrm{RR}=2.05 ; \mathrm{CI}_{95 \%}(1.35-3.11) ; \mathrm{p}<0.01\right)$, the prolonged labor $\left(\mathrm{RR}=1.38 ; \mathrm{CI}_{95 \%}(1.05-1.81) ; \mathrm{p}<0.01\right)$, the length of cesarean $\left(\mathrm{RR}=3.00 ; \mathrm{CI}_{95 \%}(1.89-4.90) ; \mathrm{p}<0.01\right)$, and genital bleeding $\left(\mathrm{RR}=1.50 ; \mathrm{CI}_{95 \%}\right.$ $(1.10-1.90) ; \mathrm{p}<0.01)$. The complications reported were endometritis (43.55\%), wound infection (18.11\%), breast infection (32.05\%), puerperal psychosis (9 cases). We recorded six cases of pelviperitonitis and three cases of sepsis. Four cases of maternal death due to septic shock have been recorded (1.43\%). Conclusion: Post cesarean infections constitute a real problem of public health in developing countries. In our survey, the main factors of infections have been context of cesarean, prolonged labor and length of cesarean. 
Endometritis, breast infection and wound infection are the major complications after cesarean section. The respect of protocol of the management of patients should permit to prevent this deadly complication.

\section{Keywords}

Fever, Postpartum, Cesarean, Endometritis, Risk Factor, Death, Mali

\section{Introduction}

Cesarean delivery is now the most commonly performed operation in hospital across the world. In United States, approximately $30 \%$ of the 4 million deliveries that occur each year are by cesarean [1]. In African countries, the same trends have been observed in different hospital rates balancing from $25 \%$ to $30 \%$ [2]. Historically, cesarean delivery was associated with a high complication rate, sometimes causing maternal death. In the era of modern medicine, however, cesarean section has become safe and is widely endorsed throughout the world as a strategy to improve pregnancy outcomes [3].

However that safe operation is often complicated by infections such as endometritis, pelviperitonitis, and wound infection. The incidence of such infections has been estimated to $2 \%$ to $16 \%$ [4] [5] [6] [7]. These infections are usually responsible of fever in post-partum. Other complications that can draw to fever are breast infection or deep thrombophlebitis. They are serious complications that increase the frequencies of postpartum morbidity and mortality, duration of hospital stay and cost of cares [8].

Potential risk factors of cesarean delivery include intra-amniotic infection, peri-operative antibiotic use, presence or duration of ruptured membranes, number of vaginal examination, elective or emergency reason for the surgery [9] and respect or no of asepsis and antisepsis rules.

In Mali, since 2005 the government has decided to subsidize the cesarean section and undertaken the training of health workers in order to improve the health of population. It has also been betted by adding antibiotic and other drugs into the composition of cesarean instruments kit.

\section{Objectives}

Regarding our working context different from that of developed countries, we have carried out that historical cohort study in order to determine trends of incidence and to analyze risk factors and describe prognosis of post cesarean infections associated to cesarean delivery.

\section{Material and Method}

\subsection{Study Setting}

Gabriel Touré teaching hospital is a tertiary care referral center in Bamako, Mali 
affiliated with the Faculty of Medicine and Odonto-stomatology and the faculty of pharmacy at the University of Bamako. This hospital provides emergency obstetric services for women referred from other health centers, as well as prenatal care and delivery services for women from urban and rural areas surrounding Bamako.

\subsection{Type of Survey and Sampling}

It was a randomized historical cohort study that took place in the department of gynecology and obstetrics of Gabriel Touré teaching hospital from 2010 to 2015.

We have defined fever in postpartum if temperature $\geq 38^{\circ}$ Celsius.

Two groups of randomization have been done. Group 1: all patients who had got infectious complications after cesarean section and Group 2: all patients who had not any got infectious complications after cesarean section. Both groups have been followed in order to appreciate risk factors and prognosis of complications linked to that infections.

Inclusion Criteria: all the cases of elective or emergency cesarean deliveries complicated by fever in the post-partum.

Exclusion criteria: all the vaginal deliveries cases.

Data were collected from the complete obstetric files, registries of on-call midwives, surgical reports, admission records for the intensive care service and records from hospital death registries.

For maternal complications, we have estimated rates of post-cesarean complications. Post-cesarean fever complications included post-cesarean infection, deep venous thrombosis, and puerperal psychosis. For surgical site infection we have adopted the CDC. Serious infection morbidity has been defined as bacteremia, septic shock, septic thrombophlebitis, necrotizing fasciitis; peritonitis, or death attributed to infection. Risk factors of fever complications in the post-cesarean infection have been studied. Univariate analyze has been used to determine risk factors (such as reference of patients, anemia, type of anesthesia, duration of labor, genital bleeding, incision of the skin, blood loss) that were associated to fever in the postpartum of cesarean. These factors are commonly mentioned in the occurrence of post cesarean infections. First we have computed crude odds ratios followed by adjusted odds ratios. After, we have adjusted each factor for potential confounders in a multivariate logistic regression model.

All calculations were performed by using SPSS version 16.0 (SPSS Inc, Chicago, IL). Data have been analyzed by using $\mathrm{X}^{2}$ or Fisher test according their application conditions, $\mathrm{p}$ value $<1 \%$ has been considered significant.

The database used for this analysis was reviewed and approved by the ethics committee of the Faculty of Medicine, Pharmacy, and Dentistry at the University of Bamako, Mali.

\section{Results}

\subsection{Incidences of Post Cesarean Infections}

From 2010 to 2015 we performed 15,963 deliveries within 5263 cesarean deliveries 
(32.97\%). Figure 1 describes annual incidence trends of caesarean (blue graphic), frequencies of post caesarean infection according all the deliveries (red graphic) and according patients who has undergone caesarean operation (green graphic). Overall cesarean rates are higher than $30 \%$. Moreover, infection rates in our service are also high. According to all the deliveries, the global frequency of infection fluctuates from $1.5 \%$ (2010) to $2.1 \%$ (2015).

\subsection{Types of Post Caesarean Infections}

Classic morbid diseases have been reported in our study especially 125 cases of endometritis (43.55\%), 52 cases of wound infection (18.11\%), 92 cases of breast infection (32.05\%), 9 cases of puerperal psychosis (3.13\%). Postpartum of our patients has been complicated by severe infection. So we recorded 6 cases (2.09\%) of pelviperitonitis and three cases of sepsis $(1.04 \%)$.

\subsection{Risk Factors of the Occurrence of Post Cesarean Infections}

Univariate analysis of factors influencing the occurrence of post cesarean infection found eight factors associated to infectious complication after cesarean. There are: context of caesarean $\left(\mathrm{RR}=1.60 ; \mathrm{CI}_{95 \%}(1.10-2.00) ; \mathrm{p}<0.01\right)$, type of anesthesia $\left(\mathrm{RR}=2.10 ; \mathrm{CI}_{95 \%}(1.88-4.10) ; \mathrm{p}<0.01\right)$, type of skin incision $\left(\mathrm{RR}=1.77 ; \mathrm{CI}_{95 \%}(1.29-1.80) ; \mathrm{p}<0.01\right)$, blood loss $\left(\mathrm{RR}=4.00 ; \mathrm{CI}_{95 \%}(2.33-\right.$ $6.70) ; \mathrm{p}<0.01)$, obesity $\left(\mathrm{RR}=3.12 \mathrm{CI}_{95 \%}(2.99-5.35) ; \mathrm{p}<0.01\right)$, genital bleeding $\left(\mathrm{RR}=5.00 ; \mathrm{CI}_{95 \%}(4.00-8.00) ; \mathrm{p}<0.01\right)$, length of cesarean $(\mathrm{RR}=$ 5.55; $\left.\mathrm{CI}_{95 \%}(5.00-10.20) ; \mathrm{p}<0.01\right)$ and prolonged labor $\left(\mathrm{RR}=3.36 ; \mathrm{CI}_{95 \%}(2.99\right.$ - 7.11); $\mathrm{p}<0.01)$. No statistical relation was found between ante natal care $(R R$ $\left.=1.44 ; \mathrm{CI}_{95 \%}(0.13-1.60) ; \mathrm{p}>0.01\right)$, anemia $\left(\mathrm{RR}=0.66 ; \mathrm{CI}_{95 \%}(0.78-2.00) ; \mathrm{p}>\right.$ $0.01)$.

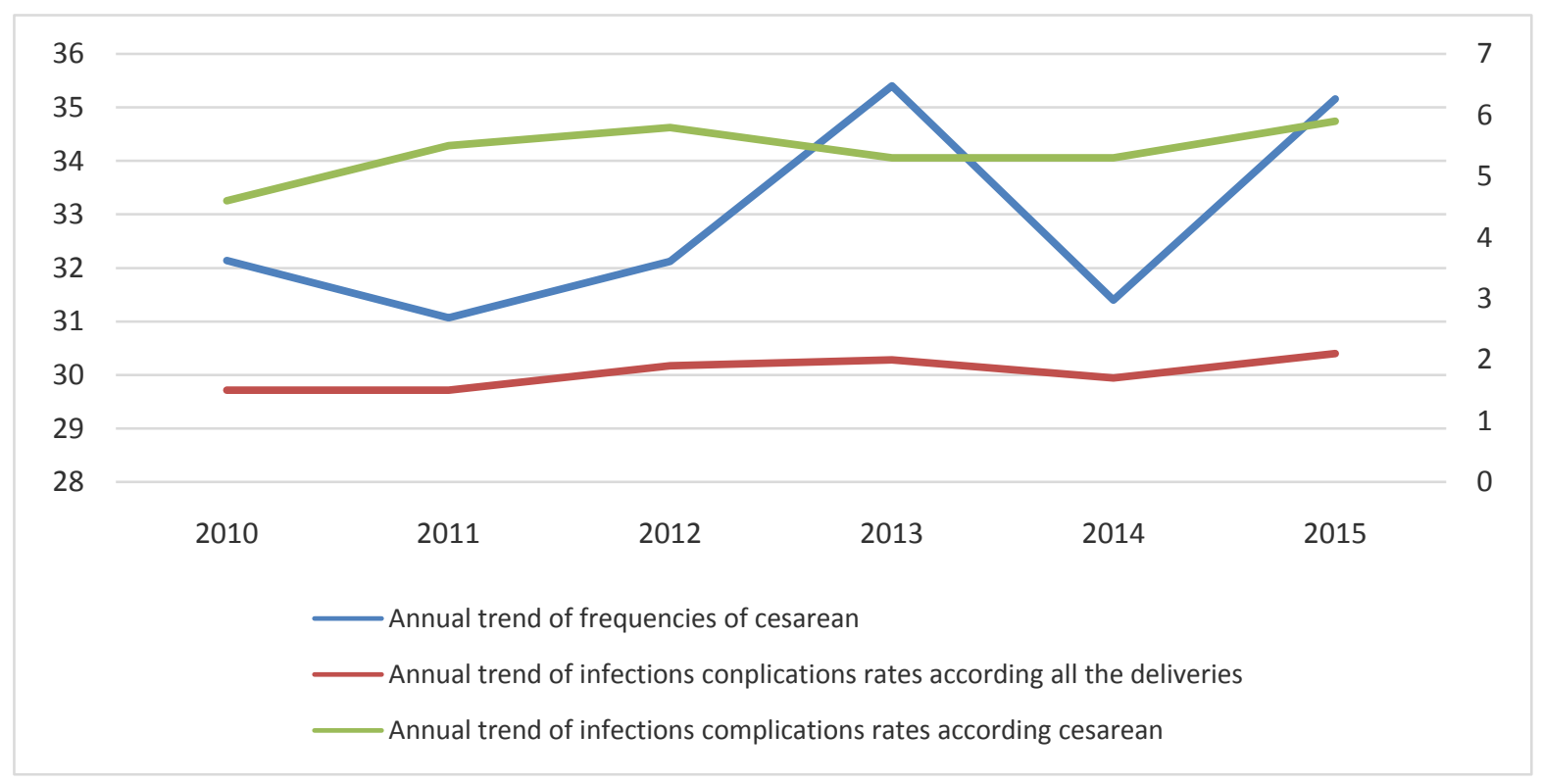

Figure 1. The trends of caesarean infectious complications during the period of study in Gabriel Touré Teaching hospital. 
In multivariate analyse, only six factors remain significantly associated to that puerperal infection (Table 1).

Multivariate analyse shown that occurrence of fever complications after caesarean are associated to caesarean practiced in emergency context $(R R=2.05 ; \mathrm{p}$ $<0.01)$, obesity $(R R=1.11 ; p<0.01)$, genital bleeding $(R R=1.50 ; p<0.01)$, length of cesarean $(R R=3.00 ; p<0.01)$, reference of patients $(R R=1.2 ; p<0.01)$ and prolonged labor $(R R=1.38 ; p<0.01)$. No statistical relation was found between type of anesthesia ( $p>0.01)$, type of skin incision $((p>0.01)$ and blood loss $(\mathrm{p}>0.01)$.

\subsection{Prognosis}

Mortality frequency related to our patients with postpartum infection was $1.43 \%$ (4 cases) that occurred after sepsis. No maternal death has occurred in the group without infection. The mean of hospitalization stay of post cesarean complicated group was 15 days (with extreme of 10 and 21 days) vs 6 days (with extreme of 4 and 7 days) in the group of patients without infectious complications.

\section{Comments-Discussion}

\subsection{Limitation of the Study}

Our study has encountered some limitation related to systematic use of anti-biotherapy in our service and the variability of the experience among surgeons who perform cesarean section. Some of them have more experience in the practice of cesarean than others. That has maybe influenced the occurrence of infectious complications in this survey.

\subsection{Annual Incidences of Cesarean and Post Cesarean Infections}

From 2010 to 2015 we performed 15,963 deliveries within 5263 cesareans sections (32.97\%). The trends of incidences in Figure 1 show clearly that our caesarean rates are globally higher than $30 \%$. Cesarean rates in hospital or referral centers are often more than $20 \%$. Review of the literature confirms that tendency: Banfora, Burkina Faso (29.51\%) [10], Cote d'Ivoire (31.03\%) [11] and Mali (25.5\%) [2]. Table 2 reports several rates in Sub Saharan countries.

All these data explain why cesarean delivery is now the most commonly performed operation in hospital [1].

Although conditions of cesarean operation have been improved, this intervention is at risk. One of the mains complications of this intervention is maternal morbidity related to puerperal infection. Many studies have reported variable frequencies of that complication after cesarean. For Kelley [16], the primary risk factor of puerperal infection is cesarean delivery, which increases its risk 5 to 20 fold. A number of sources exist for postoperative infectious morbidity following cesarean such as urinary tract infection, pneumonia, drug fever [16] and malaria that is more specifically met in tropical countries. In this retrospective cohort 
Table 1. Risk factors of post cesarean infections in our study.

\begin{tabular}{|c|c|c|c|}
\hline Factors & Relative risk & 95\% Confidence Interval & $P$ value \\
\hline \multicolumn{4}{|l|}{ Referred of patients } \\
\hline Yes & 1.2 & $0.94-1.52$ & $<0.01$ \\
\hline \multicolumn{4}{|l|}{ No } \\
\hline \multicolumn{4}{|l|}{ Body Mass Index } \\
\hline $18-25$ & 1.11 & $0.86-1.42$ & $<0.01$ \\
\hline \multicolumn{4}{|l|}{$26-40$} \\
\hline \multicolumn{4}{|l|}{ Genital bleeding } \\
\hline Yes $(n=892)$ & 1.5 & $1.1-1.9$ & $<0.01$ \\
\hline \multicolumn{4}{|l|}{ No $(\mathrm{n}=4371)$} \\
\hline \multicolumn{4}{|l|}{ Prolonged labor } \\
\hline Yes $(n=1135)$ & 1.38 & $1.05-1.81$ & $<0.01$ \\
\hline \multicolumn{4}{|l|}{ No $(n=4128)$} \\
\hline \multicolumn{4}{|l|}{ Type of anesthesia } \\
\hline General & 1.55 & $1.18-2.05$ & $>0.01$ \\
\hline \multicolumn{4}{|l|}{ Loco-regional } \\
\hline \multicolumn{4}{|l|}{ Context of caesarean } \\
\hline Emergency $(n=4423)$ & 2.05 & $1.35-3.11$ & $<0.01$ \\
\hline \multicolumn{4}{|l|}{ No emergency $(n=840)$} \\
\hline \multicolumn{4}{|l|}{ Type of skin incision } \\
\hline Median incision $(\mathrm{n}=647)$ & 1.35 & $0.97-1.87$ & $>0.01$ \\
\hline \multicolumn{4}{|l|}{ Transversal incision $(\mathrm{n}=4616)$} \\
\hline \multicolumn{4}{|l|}{ Blood loss } \\
\hline Less than $1000 \mathrm{ml}(\mathrm{n}=4112)$ & 0.97 & $0.73-1.29$ & $>0.01$ \\
\hline \multicolumn{4}{|l|}{ More than $1000 \mathrm{ml}(\mathrm{n}=1151)$} \\
\hline \multicolumn{4}{|l|}{ Length of caesarean } \\
\hline Less than 60 minutes $(\mathrm{n}=3845)$ & 3.00 & $1.89-4.90$ & $<0.01$ \\
\hline More than 60 minutes $(n=1418)$ & & & \\
\hline
\end{tabular}

Table 2. Cesarean delivery rates in different settings in sub Saharan African countries.

\begin{tabular}{ccc}
\hline Authors & Site of study & Rates of cesarean \\
\hline Kwawukume, [12] & Ghana & $23.8 \%$ \\
Bambara et al. [13] & Burkina Faso & $11.3 \%$ \\
Cissé et al. [14] & Senegal & $25.1 \%$ \\
Muganyizi [15] & Tanzania & $25.6 \%$ \\
Our study & Mali & $32.97 \%$
\end{tabular}

study, we have found that the rate of infection in our service is high. Indeed, according to all the deliveries (red graphic) the global frequency of infection fluctuated from $1.5 \%$ in 2010 to $2.1 \%$ in 2015. In his study from 1985 to 2003, Teguete [2] found $20.1 \%$ of postpartum infection among cesarean deliveries versus $3.9 \%(509 / 13204)$ for vaginal deliveries ( $\mathrm{OR}=6.3$ [5.6 - 7.1], $\mathrm{p}<0.001)$.

The causes of puerperal infections are numerous. The main causes noted in our study are in Figure 2. Endometritis (43.55\%), wound infection (18.11\%) 


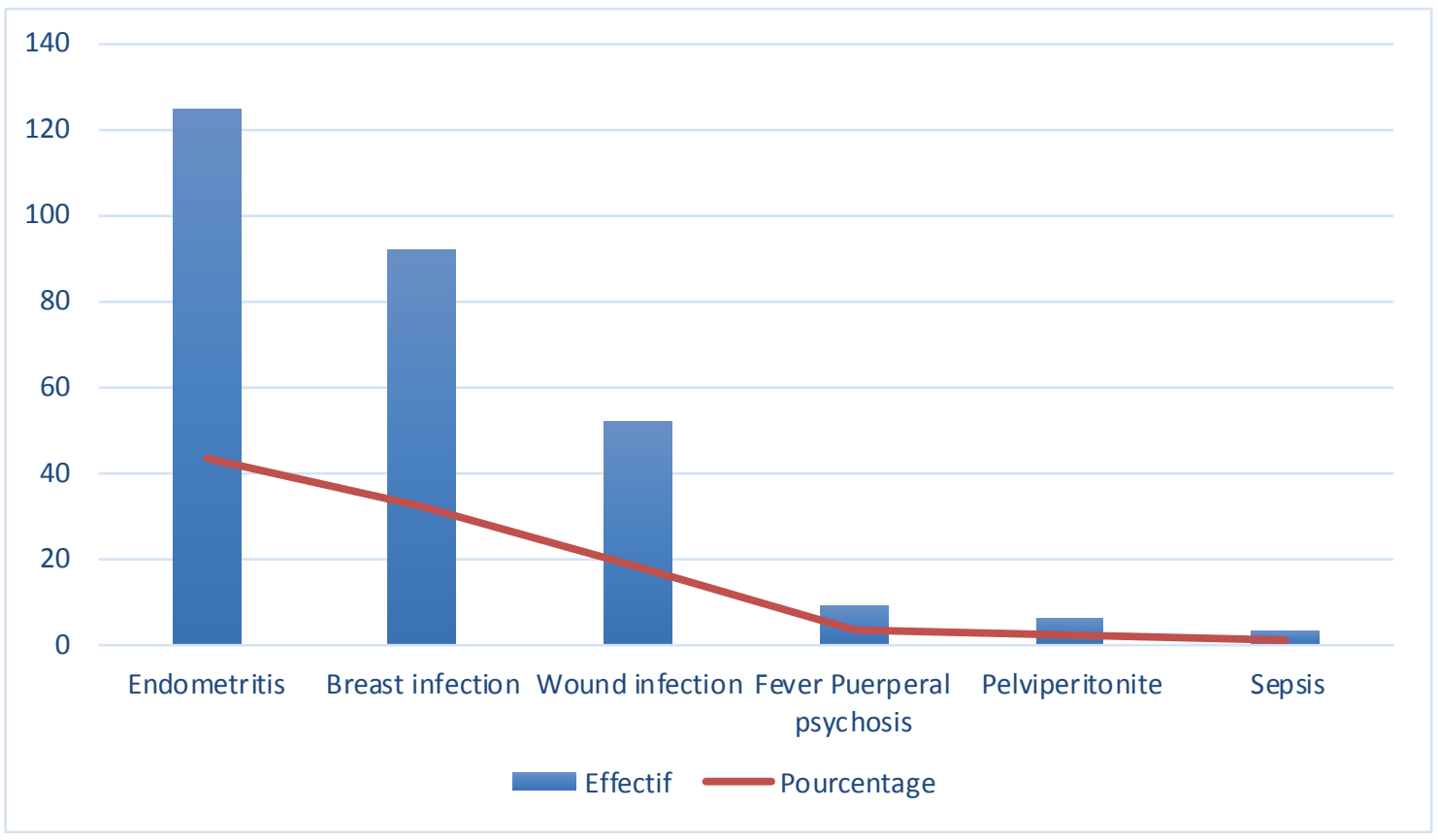

Figure 2. Types of infectious complications after cesarean delivery in Gabriel Touré Teaching hospital from 2010 to $2015(\mathrm{n}=287)$.

[1] [2] [16] [17] [18] and mastitis (32.05\%) constituted the most frequent. Other complications noted in our study are puerperal psychosis related to fever, deep infection of the pelvis or abdomen and sepsis. Our endometritis rate is higher than those reported in developed countries as we can notice in the reports of authors such as Thuman [19] (5.4\%) and Mah [20]. For Teguete [2], endometritis, peritonitis, and serious infectious morbidity were more linked to abdominal route of delivery.

Despite the use of antibio-prophylactic and the improvement of conditions of cesarean in our African context, puerperal infection still remains very high. Puerperal psychosis seems to be less frequent in the post cesarean period. That has been illustrated in other survey [2].

\subsection{Risk Factors and Prognosis}

In this survey we have critically analyzed factors influencing the occurrence of post cesarean infections. So many factors have been found associated to the occurrence of the post caesarean infection as it is shown in Table 1. Most of authors in several studies have reported many risk factors that are associated to post cesarean infection (Table 3 ).

Although all the women are at risk for infection in the postpartum period, not all are equal risk. That explains, at least in part, why the reported incidence of post cesarean infections morbidity varies so widely in the literature that shows data above [16].

In our study regarding data from Table 1 , six risk factors were finally associated to post cesarean infection. Indeed, the conditions of admission of the patient, 
Table 3. Risk factors of post cesarean infectious morbidity in the literature.

\begin{tabular}{ccc}
\hline Variables & OR $(95 \% \mathrm{IC})$ & Authors \\
\hline Cesarean versus vaginal delivery & $4.71(4.08-5.43)$ & Leth et al. [21] \\
Emergency versus elective cesarean delivery & $1.39(1.11-1.75)$ & Leth et al. [21] \\
Presence of PROM ${ }^{*}$ & $3.13(1.34-7.38)$ & Chang et al. [22] \\
Obesity & $1.60(1.31-1.95)$ & Kelley [16] \\
Length of cesarean $(>60$ min vs $\leq 60 \mathrm{~min})$ & $1.9(1.1-3.5)$ & Teguete et al. [2] \\
Abnormal amniotic fluid coloration & $3.3(2.7-3.39)$ & Teguete et al. [2] \\
\hline
\end{tabular}

prolonged labor, context of cesarean if realized in emergency or no, vaginal bleeding and high body mass index have been statistically associated to fever after cesarean in our survey. When labor is prolonged, risk of vaginal and amniotic fluid infection will occur and lead to puerperal infection after the delivery. Although an increased duration of surgery has been associated with higher rates of infection [22], for Kelley [16], this heavily depends on maternal predisposing, such as obesity or prior surgeries resulting in dense adhesions. Body mass index is more associated to wound infections, especially among patient with diabetes or severe hypertension.

For obstetric population, we only found length of cesarean up than sixty minutes linked to post cesarean infection. However we agree with Teguete et al. [2], Heather et al. [17], and Chang et al. [22] that premature rupture of membrane, abnormal amniotic fluid coloration constitutes some important risk factors of infection after cesarean section.

Maternal mortality remains a serious problem of health especially in developing countries. Puerperal infection is one of the leading causes of this mortality [23] [24]. In our study, we have recorded 4 maternal deaths that occurred among patient with sepsis. The prognosis of women who had vaginal delivery was better than women who have been operated (group1).

\section{Conclusion}

Puerperal infection remains a major problem of health in our country. Many risk factors of these complications are reported in this survey such as context of cesarean, prolonged labor, PROM, and length of cesarean. Endometritis, breast infection and wound infection are the mains infectious complications after cesarean in our service. Maternal prognosis was poor because of maternal death rate that is still high. A best practice of the management of the patients in general and particularly that of patients who have undergone cesarean should permit to avoid this deadly complication. Our study suggests the improvement of the reference of patients, the use of partograph for monitoring labor and finally the respect of the rules of the prevention of infections during delivery.

\section{References}

[1] Kathryn, E.P., Sara, L.D. and Patrick, D. (2016) Preventing Infection after Cesarean 
Delivery: Evidence-Based Guidance. OBG Management, 5, 1-8.

[2] Teguete, I., Traore, Y., Sissoko, A., Djire, M.Y., Thera, A., Dolo, T., Mounkoro, N., Traore M. and Dolo, A. (2010) Determining Factors of Cesarean Delivery Trends in Developing Countries: Lessons from Point G National Hospital (Bamako-Mali). Open Technologies, 9, 161-200.

[3] Weil, O. and Fernandez, H. (1999) Is Safe Motherhood an Orphan Initiative? Lancet, 354, 940-943. https://doi.org/10.1016/S0140-6736(99)02369-7

[4] Emmons, S.L., Krohn, M., Jackson, M. and Eschenbach, D.A. (1988) Development of Wound Infections among Women Undergoing Cesarean Section. Obstetrics \& Gynecology, 72, 559-564.

[5] Webster, J. (1988) Post-Caesarean Wound Infection: A Review of the Risk Factors. The Australian and New Zealand Journal of Obstetrics and Gynaecology, 28, 201-206. https://doi.org/10.1111/j.1479-828X.1988.tb01664.x

[6] Loong, R.L.C., Rogers, M.S. and Chang, A.M.Z. (1988) A Controlled Trial on Wound Drainage in Caesarean Section. The Australian and New Zealand Journal of Obstetrics and Gynaecology, 28, 266-269. https://doi.org/10.1111/j.1479-828X.1988.tb01679.x

[7] Ducel, G., Fabry, J., Nicolle, L., et al. (2002) Prevention of Hospital-Acquired Infections. A Practical Guide. 2nd Edition, WHO/CDS/CSR/EPH, Geneve, 80 p.

[8] Mangram, A.J., Horan, T.C., Pearson, M., et al. (1999) Guideline for Prevention of Surgical Site Infection. Infection Control and Hospital Epidemiology, 4, 247-278. https://doi.org/10.1086/501620

[9] Stephen, T.V., Carlos, L., David, E.S. and Ana, V. (2000) Wound Infection after Cesarean: Effect of Subcutaneous Tissues Thickness. Obstetrics and Gynecology, 95, 923-926.

[10] Ouattara, A., Yaméogo, R.B., Kaboré, F.X.G., Kiemtoré, S., Kain, D.P., Sawadogo, Y.A., Dao, Y., Ouedraogo, I., Ouédraogo, C.M., Ouédraogo, A., Millogo, T.F. and Thieba, B.B. (2017) Prognosis of Misgav-Ladach Caesarean Sections in an African Environment: Case of the Banfora Regional Hospital in Burkina Faso about 110 Cases. Open Journal of Obstetrics and Gynecology, 7, 1006-1015. https://doi.org/10.4236/ojog.2017.79101

[11] Bokossa, M., Nguessan, K., Doumbia, Y., Kacou, C., Djoubou, C. and Boni, S. (2008) Prophylactic and Urgent Caesareans: About 394 Cases in U.T.H of Cocody. Médecine Afrique Noire, 11, 593-601.

[12] Kwawukume, E.Y. (2001) Cesarean Section in Developing Countries. Best Practice \& Research Clinical Obstetrics \& Gynaecology, 1, 165-178. https://doi.org/10.1053/beog.2000.0155

[13] Bambara, M., Fongan, E., Dao, B., Ouattara, H., Lankoande, J. and Kone, B. (2007) Cearean in African Era: About 440 Cases at the Motherhood of CHUSS of Bobo-Dioulasso (Burkina Faso). Médecine Afrique Noire, 6, 343-348.

[14] Cissé, C.T., Ngom, P.M., Guissé, A., Faye, E.O. and Moreau, J.C. (2004) Thinking about the Evolution of Cesarean Section Rate at University Teaching Hospital of Dakar between 1992 and 2001. Gynécologie Obstétrique \& Fertilité, 3, 210-217. https://doi.org/10.1016/j.gyobfe.2003.12.013

[15] Muganyizi, P.S. and Kidanto, H.L. (2009) Impact of Change in Maternal Age Composition on the Incidence of Cesarean Section and Low Birth Weight: Analysis of Delivery Records at a Tertiary Hospital in Tanzania, 1999-2005. BMC Pregnancy and Childbirth, 9, 30. https://doi.org/10.1186/1471-2393-9-30 
[16] Conroy, K., Koenig, A.F., Yu, Y.H., Courtney, A., Lee, H.J. and Norwitz, E.R. (2012) Infectious Morbidity after Cesarean Delivery: 10 Strategies to Reduce Risk. Reviews in Obstetrics and Gynecology, 2, 69-77.

[17] Heather, D.W., Marijane, A.K., Sharon, L.H. and David, A.E. (1990) Bacterial Vaginosis as a Risk Factor for Cesarean Endometritis. Obstetrics and Gynecology, 1, 52-58.

[18] Traore, Y., Traore, D., Teguete, I. Mounkoro, N., Togo, A., Djire, M.Y., Sissoko, A., Diallo, A., Bagayoko, M.A., Dolo, T. and Dolo, A. (2012) Indications and Prognosis of Caesarean Section among HIV Infected Patients in Gynecology and Obstetrics Service of Gabriel Toure Teaching Hospital between 2003 to 2009. Annales de la SOGGO, 7, 13-18.

[19] Thurman, A.R., Anca, Y., White, C.A. and Soper, D.E. (2010) Post Cesarean Delivery Infectious Morbidity: Focus on Preoperative Antibiotics and Methicillin-Resistant Staphylococcus aureus. American Journal of Infection Control, 38, 612-616. https://doi.org/10.1016/j.ajic.2010.02.013

[20] Mah, M.W., Pyper, A.M., Oni, G.A. and Memish, Z.A. (2010) Impact of Antibiotic Prophylaxis on Wound Infection after Cesarean Section in a Situation of Expected Higher Risk. American Journal of Infection Control, 29, 85-88. https://doi.org/10.1067/mic.2001.111372

[21] Leth, R.A., Møller, J.K., Thomsen, R.W., et al. (2009) Risk of Selected Postpartum Infections after Cesarean Section Compared with Vaginal Birth: A Five-Year Cohort Study of 32.468 Women. Acta Obstetricia et Gynecologica Scandinavica, 88, 976-983. https://doi.org/10.1080/00016340903147405

[22] Chang, P.L. and Newton, E.R. (1992) Predictors of Antibiotic Prophylactic Failure in Post-Cesarean Endometritis. Obstetrics \& Gynecology, 80, 117-122.

[23] Belío-Blasco, C., Torres-Fernández-Gil, M.A., Echeverría-Echarri, J.L. and GómezLópez, LI. (2000) Evaluation of Two Retrospective Active Surveillance Methods for the Detection of Nosocomial Infection in Surgical Patients. Infection Control \& Hospital Epidemiology, 21, 24-27. https://doi.org/10.1086/501692

[24] Teguete, I., Traore, Y., Dennis, N., Mounkoro, N., Traore, M. and Dolo, A. (2010) A 19-Year Retrospective Investigation of Maternal Mortality at Point G National Hospital, Bamako, Mali. International Journal of Gynaecology and Obstetrics, 108, 194-198. https://doi.org/10.1016/j.ijgo.2009.09.026 